\title{
Quantification of capillary water input to the root zone from shallow water table and determination of the associated Bartlett pear water status
}

\author{
Maria Lucia Mañueco ${ }^{1}$, Andrea Rodríguez ${ }^{1}$, Ayelen Montenegro ${ }^{1}$, Juan Galeazzi ${ }^{2}$, \\ Dolores Del Brio ${ }^{1}$, Mariela Curetti ${ }^{1}$, Ángel Muñoz ${ }^{1}$ and Maria Dolores Raffo ${ }^{1}$ \\ ${ }^{1}$ INTA EEA Alto Valle, CC 782, CP8332, General Roca, Rio Negro, Argentina \\ ${ }^{2}$ Facultad de Ciencias Agrarias, Universidad Nacional del Comahue, Argentina
}

Keywords: soil water balance, stomata conductance, moisture stress index.

The Alto Valle of Rio Negro and Neuquén is an intensive irrigated fruit producing area. The existence of a shallow water table modifies the water content in the soil profile. It is important to distinguish the effect and estimate the amount of water capillary rise in order to enhance the irrigation management and allow the crop to achieve its maximum yield and development in non-stress conditions. The aim of this trial was to quantify and associate water content of soil profile with water status of pear trees, using different methods. In a Bartlett pear orchard planted on 2003, surfaced irrigated, the following variables were measured during the 2017-2018 growing season: soil water content at three depths $(0.20 \mathrm{~m}, 0.40 \mathrm{~m}, 0.60 \mathrm{~m})$ and water table level (WTL). Additionally, soil profile and texture class were described. Evapotranspiration (ETm) and vapor pressure deficit (VPD) were calculated with data of the automatic weather station. Stomata conductance (Gs) was measured with a leaf porometer in three different moments of the growing season. Moisture stress index (MSI) was calculated from all Sentinel 2A images available for the season. The capillary water input into the root zone from a shallow water table is evident in the continuous records of sensors. This phenomenon keeps soil water content within the readily available water range. The Gs measures showed that the crop water status was appropriate and that values were high compared to those referred to deciduous trees. The MSI values obtained were between the limits of a well-irrigated crop. These results agree with the non-restrictive condition observed in the soil water balance.

Publicado originalmente en: Mañueco, M.L.; Rodríguez, A.; Montenegro, A.; Galeazzi, J.; D. del Brio, D.; Curetti, M.; Muñoz, A.; Raffo, M.D: Quantification of capillary water input to the root zone from shallow water table and determination of the associated Bartlett pear water status. Presentado en: XIII International Pear Symposium. Montevideo, Uruguay, 4 - 7 diciembre 2018 (Trabajo completo en publicación). 